\title{
Validity, Reliability, Predictors, Moderation: The UTAUT Model Revisited
}

\begin{abstract}
Hamed A. Alshahrani
King Khalid University, Saudi Arabia

David A. Walker

Northern Illinois University

Based on the Unified Theory of Acceptance and Use of Technology, this study investigated if performance expectancy (PE), effort expectancy (EE), and social influence (SI) were predictors of students' behavioral intentions (BI) to adopt M-learning in Saudi Arabian higher education. In addition, the potential moderating effect of gender in the model was also considered and tested. A total of 848 students from King Khalid University, Saudi Arabia participated in the study. As supported by previous findings from the literature, the results from the current research indicated that all three of the aforementioned factors were statistically significant, positive determinants of behavioral intention to use M-learning. Furthermore, it was found that gender moderated the relationship between PE and BI and SI and BI, but not the relationship between EE and BI. The model's internal score structure was determined to be robust.
\end{abstract}

onventionally, mobile device technologies have been designed to be autonomous, small in physical manifestation, and portable for the purpose of ubiquity. This latter point of portability is particularly relevant for higher education student learners (Dahlstrom \& Bichsel, 2014). Examples of mobile technologies used in higher education include smartphones, iPads, digital cameras, mobile apps, tablets, and short message service (i.e., text messaging). Consequently, these devices have become more prevalent and affordable in the United States and also worldwide (Poushter, 2016). Trends in using mobile technologies for teaching and learning processes (i.e., mobile learning or M-learning), for instance, but also for universal functionality are steadily increasing. For example in the United States, the specific mobile technology of a smartphone has seen ownership of this particular device increase precipitously from just 35\% possession in 2011 to 77\% in 2016 (Pew Research Center, 2016).

To be sure, portability and affordability are principal benefits offered by these technologies; making mobile devices easily utilized by higher education student learners (Chen, Seilhamer, Bennett, \& Bauer, 2015). Schepman, Rodway, Beattie, and Lambert (2012) found that due to their pervasive nature and ability to shape information processes, mobile devices were already a valuable element within higher education. Further, mobile devices, and their propagation in learning spaces, support the transmission and delivery of content in an added pervasive fashion by providing students with various educational experiences through a more comprehensive learning management system (Dahlstrom \& Bichsel, 2014)

\section{Mobile Device Technology and Saudi Arabia}

The number of mobile device technologies transported throughout the world has been increasing every year. For instance, reports by the International Telecommunication Union (ITU) showed that the smartphone permeation rate in Saudi Arabia was forecasted to increase from 25\% in 2011 to almost double this, or 49\%, by the end of 2016 (ITU, 2012). The Communications and Information Technology Commission (2015) projected that the number of mobile subscriptions in Saudi Arabia would surpass 71 million by the end of 2016 while, in comparison, this total was nearly $30 \%$ less, or 51 million subscriptions, in 2011.

\section{M-Learning and Higher Education}

Due to the evolution of handheld, portable devices and wireless technology, M-learning has become an increasingly prevalent learning approach in higher education via affording digital content and teaching materials to students and instructors. Wang, Wu, and Wang (2009) defined 'M-learning' as “... the delivery of learning to students anytime and anywhere through the use of wireless Internet and mobile devices" (p. 93). Thus, in essence, M-learning is considered also to be spontaneous, informal, contextual, and personal. Due to these qualities, M-learning has removed the obstacles of location and time, where learners are free to access course content expediently (El-Hussein \& Cronje, 2010).

Additionally, the ubiquity of wireless communication, smart phones, and tablet-based M-learning allow teaching and learning to extend to spaces beyond the traditional classroom. The critical difference between M-learning and other mediums of educational activities lies in the assumption that learners may be continually in motion (Sharples, Taylor, \& Vavoula, 2007). This important characteristic of ubiquity 
gives students the opportunity to learn at their "proper" time and place (Peng, Su, Chou, \& Tsai, 2009). The concept of ubiquity within the context of M-learning refers to 'widespread,' 'just-in-time,' and 'when-needed' computing power for learners (Peng et al., p. 175). Therefore, the ubiquity of these devices, along with their popularity among students, makes them highly sought after for use in educational contexts (El-Hussein \& Cronje, 2010) due to their ability to shape information processes (Schepman et al., 2012).

\section{User Acceptance of M-Learning}

Research on user acceptance of M-learning is still in fairly limited quantity (Liu, Han, \& Li, 2010). M-learning in the context of higher education is in its early stage of implementation, especially in developing countries such as Saudi Arabia. Attempts to apply technology acceptance theory and models to explain students' intentions to use M-learning in a higher education context have been limited; therefore, researchers such as Wang et al. (2009) suggested that further research is needed. According to Wang et al., the success of M-learning depends greatly on whether users are willing to adopt it in an educational context; particularly within higher education.

It has been acknowledged for decades (Dillon \& Morris, 1996) the importance of understanding motives pertaining to why users accept technology since this can assist in improving the design, evaluation, and prediction of how users will respond to a new technology. In the context of M-learning, user acceptance and adoption can be expressed as the willingness of students or instructors to use mobile device technologies to support teaching and learning endeavors. Students' acceptance and use of Mlearning introduced in their academic settings is a significant factor in determining its success.

\section{User Intention with M-Learning}

According to Krueger and Brazeal (1994), intention has been found to be the paramount predictor of individual behaviors. Intention is defined as an individual's willingness to pursue a given behavior and represents an individual's commitment towards the target behavior (Krueger \& Brazeal). Thus, it is essential to understand students' intentions because the success or failure of M-learning can depend on how well they like it, how easy it is to use, and how useful it is toward achieving their educational goals. Therefore, as a first step in the process of implementing M-learning in higher education, it is crucial to investigate students' intention to use M-learning.

\section{Unified Theory of Acceptance and Use of Technology}

There have been numerous theoretical models designed to assist in understanding how and why technology is accepted (i.e., actual use) as well as the intention to use it (i.e., intentional perception). Venkatesh, Morris, Davis, and Davis (2003) proposed the Unified Theory of Acceptance and Use of Technology (UTAUT) model. It is noted by Moghavvemi, Salleh, Zhao, and Mattila (2012) that the UTAUT model is an amalgamation derived from the elements of preceding models in chronological order of development: the diffusion of innovations theory (Rogers, 1962), the theory of reasoned action (Fishbein \& Ajzen, 1975), the social cognitive theory (Bandura, 1986), the technology acceptance model (TAM) (Davis, 1989), the theory of planned behavior (TPB) (Ajzen, 1991), the model of personal computer utilization (Thompson, Higgins, \& Howell, 1991), the motivational model (Davis, Bagozzi, \& Warshaw, 1992), and the TAM and TPB model blend (Taylor \& Todd, 1995). Note for a preceding and more comprehensive examination of these aforesaid models, see Wang et al. (2009) and Jairak, Praneetpolgrang, and Mekhabunchakij (2009).

The UTAUT model consists of core determinants of behavioral intention (BI): performance expectancy (PE), effort expectancy (EE), social influence (SI), and facilitating conditions (Venkatesh et al., 2003). Further, this model suggests that the effect of these core determinants are moderated by gender, age, experience, and voluntariness of use (Venkatesh et al.; Wang et al., 2009). Foundationally, UTAUT is a model of technology adoption that seeks to explain the intention of the user to employ information systems and subsequent usage behavior.

The UTAUT model has been empirically validated by a number of studies (Chen, 2011; Irby \& Strong, 2013; Moran, Hawkes, \& El Gayar, 2010; Wang \& Wang, 2010). Furthermore, the UTAUT model has investigated students' intention to use various technologies such as mobile services and devices (Jairak et al., 2009; Lowenthal, 2010), short message services (Baron, Patterson, \& Harris, 2006), mobile commerce (Chong, 2013), and tablets (Anderson, Schwager \& Kerns, 2006). This literature-based 
trend suggests that the UTAUT model is applicable in investigating the determinants of M-learning acceptance in the context of higher education.

\section{Performance Expectancy}

\section{UTAUT Constructs}

Contextually, PE suggests that individuals will find M-learning useful because it enables them to access information quickly, at a time and place of their convenience, and on the device of their choice (Donaldson, 2011). Venkatesh et al. (2003) found that PE was the most robust predictor overall within UTAUT. Wang et al. (2009) and Lowenthal (2010) both determined that PE strongly predicted behavioral intention to use M-learning. Venkatesh, Morris, and Ackerman (2000) found that PE and BI were moderated by the variable gender.

\section{Effort Expectancy}

Marchewka, Liu, and Kostiwa (2007) found EE to be more salient in the beginning stages of using new information technology. Venkatesh et al. (2003) determined that EE was a weak predictor overall within the UTAUT framework. Previous studies also indicated that EE had a moderate, positive, predictive relationship to BI (Lowenthal, 2010; Wang et al., 2009). Marchewka et al. suggested that the relationship between EE and BI was moderated by the variables gender, age, and experience.

\section{Social Influence}

Abu-Al-Aish and Love (2013) determined that a student's behavioral intention decision was frequently influenced by peer students or by other social influences such as instructors and parents. Venkatesh et al. (2003) found that SI had a small, positive, predictive relationship to BI.

\section{Behavioral Intention}

$\mathrm{BI}$ is a participant's perceived intention to use a system for M-learning, but BI is not a direct measure of actual participant usage.

\section{Research Purpose}

\section{Research Purpose, Research Questions, and Hypotheses}

Contextually, the motivation affiliated with this research was to explore Saudi Arabian, undergraduate, higher education students' perceived intention to use M-learning to examine if a launch of a mobile devices M-learning project was reasonable. Thus, there was a need to garner research pertaining to students' behavioral intentions related to using M-learning in their educational, university environment and learning spaces.

\section{Research Questions}

The UTAUT model was chosen as the framework for this study because it has been found to explain from $28 \%$ to $70 \%$ of the variance in user behavioral intention (Abu-Al-Aish \& Love, 2013; Mtebe \& Raisamo, 2014; Venkatesh et al., 2003; Wang et al., 2009). Based on the UTAUT model and the scholarly literature in the field, it is projected that PE, EE, and SI will predict students' behavioral intention to adopt M-learning for academic purposes in a Saudi Arabian university. In addition, the potential moderating effect of gender in the model will also be considered and tested.

The following research questions were used to guide the study:

1). To what extent do PE, EE, and SI predict students' behavioral intention to use M-learning in a Saudi Arabian university? and $\mathrm{SI}$ and $\mathrm{BI}$ ?

2). To what extent does gender moderate the relationships between PE and BI, EE and BI,

\section{Hypotheses}

The following hypotheses, depicted in Figure 1, will be tested within a multiple linear regression (MLR) model with potential moderation from the variable gender in subsequent models:

$\mathrm{H}_{1}$ : PE, EE, and SI will be predictors of Saudi Arabian students' BI toward using M-learning.

$\mathrm{H}_{2}$ : The relationship between $\mathrm{PE}$ and BI will be moderated by gender.

$\mathrm{H}_{3}$ : The relationship between EE and BI will be moderated by gender.

$\mathrm{H}_{4}$ : The relationship between SI and BI will be moderated by gender. 
Alshahrani \& Walker

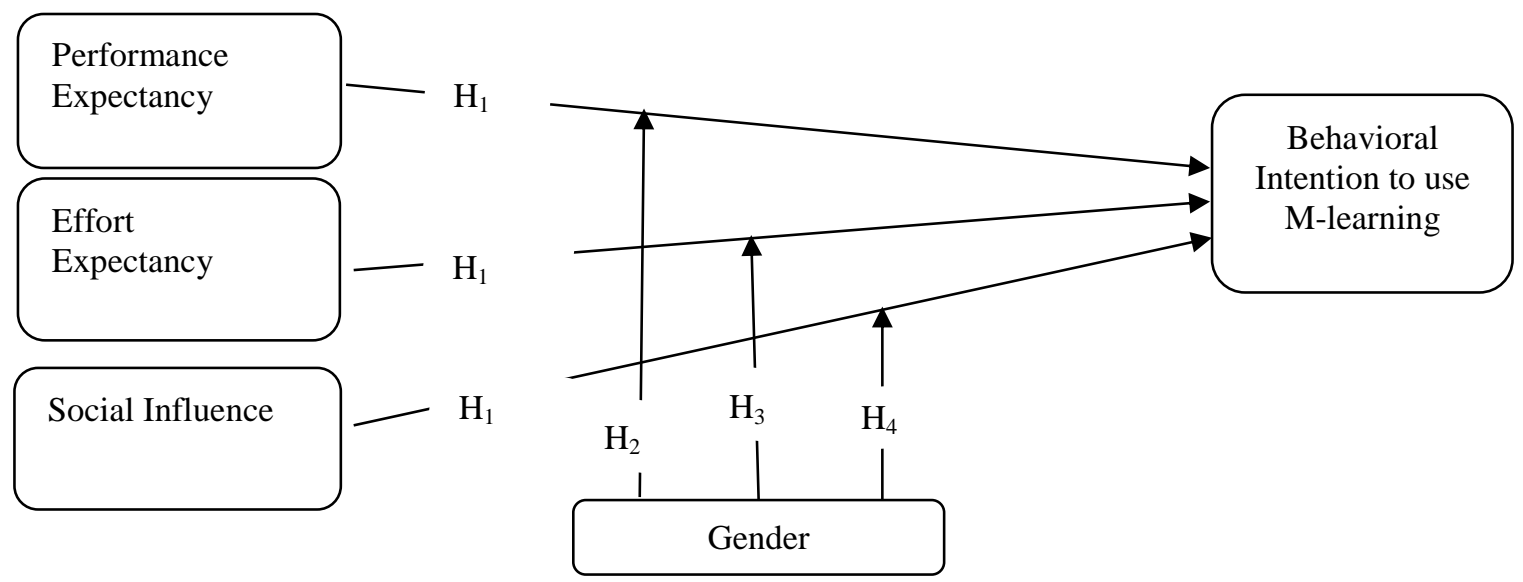

Figure 1. The multiple linear regression research model with the moderator gender.

Note. The UTAUT's facilitating conditions construct was not part of this research model nor where the infrequently-used age and experience moderators (Venkatesh, Thong, \& Xu, 2012)

\section{Survey Instrument}

\section{Methods}

A self-administered, online survey was conducted to collect data and was divided into two sections. The first section consisted of demographic items concerning participant characteristics related to gender, age, experience using handheld devises, and Internet access from handheld devices. The second section included items used to ascertain the perceptions of Saudi Arabian undergraduate students regarding their behavioral intentions to use mobile learning. A total of 15 items (see Table 2) were employed and adopted from the original protocol by Venkatesh et al. (2003) as well as a modified version by Mtebe and Raisamo (2014), and based on a 5-point rating scale: 1=Strongly Disagree; 2=Disagree; 3=Neutral; 4=Agree; and 5=Strongly Agree. Lastly, opened-ended questions were posed at the conclusion of the protocol as elements for identifying potential implications for practice affiliated with M-learning.

\section{Population and Sample}

This survey research study was designed to investigate the determinants that predict the behavioral intentions of undergraduate students from a university in Saudi Arabia to adopt M-learning using the UTAUT model. Employing a convenience sample, the entire undergraduate, accessible student population $(72,000)$ from King Khalid University (KKU) in Saudi Arabia was invited via e-mail to participate in the online survey. To determine the minimum sample size required for this study, an a priori statistical power analysis using G*Power (Faul, Erdfelder, Buchner, \& Lang, 2009; Faul, Erdfelder, Lang, \& Buchner, 2007) was conducted. For the overall MLR model predicated on an alpha level established at .05, minimum power set at .80 , a moderate MLR effect size (.15) anticipated, and three predictors, the suggested minimum number of participants was $\mathrm{N}=77$. After two rounds of data collection and online follow-up with the accessible population, comprised of about 6 weeks in duration, a total of $848 \mathrm{KKU}$ undergraduate students participated in the survey. All participant data were complete.

\section{Demographic Information}

\section{Results}

Highlighted demographic results from Table 1 indicated that $59.30 \%$ of the respondents were male. Regarding respondents' age category, those between the ages of 21 to 23 years constituted the largest group of respondents at $48.60 \%$. Those who were older than 23 years accounted for $24.40 \%$ of the total respondents, which was the lowest rate within this category. With regard to the years of experience in using handheld devises, $42.50 \%$ of participants used handheld devices for more than six years, which may indicate that this prior mobile operation experience may have an 'impact' on their acceptance of Mlearning technology. Only $7.90 \%$ of the participants had less than one year's of experience in using handheld devises. The majority of participants (55.40\%) indicated that they accessed the internet from 
their handheld devices more than 10 hours per week and only $2.20 \%$ of the participants reported that they had not accessed the internet from their handheld devices.

\section{Descriptive Statistics: Constructs and Items}

Overall, the descriptive statistics results indicated that participants were quite agreeable with the vast majority of the items on the survey. Because UTAUT researchers frequently average sub-scale item scores (i.e., weighting the items as equivalent) to form composite variables, we examined the mean composite score for each construct, where $\mathrm{BI}$ had the highest scale score $(\mathrm{M}=$ 4.13, $\mathrm{SD}=.88)$ with $\mathrm{EE}(\mathrm{M}=3.95, \mathrm{SD}=$ $.74), \mathrm{PE}(\mathrm{M}=3.84, \mathrm{SD}=.85)$, and $\mathrm{SI}(\mathrm{M}=$ $3.41, \mathrm{SD}=.84$ ) following sequentially. Further, Table 2 specified that the individual survey items with the top three highest agreement scores were all from either the BI or the EE constructs: BI - "I predict that I would use M-Learning in the future" $(\mathrm{M}=$ $4.15, \mathrm{SD}=.91)$; "If available, I plan to use

Table 1. Participant Demographic Characteristics

\begin{tabular}{|c|c|c|c|}
\hline Demographic & Categories & Frequency & $\%$ \\
\hline \multirow[t]{2}{*}{ Gender } & Male & 503 & 58.9 \\
\hline & Female & 351 & 41.1 \\
\hline \multirow[t]{3}{*}{ Age } & 18- 20 years & 231 & 27.0 \\
\hline & $21-23$ years & 413 & 48.4 \\
\hline & $<23$ years & 210 & 24.6 \\
\hline \multicolumn{2}{|c|}{ Experience Using Less than one year } & 67 & 7.8 \\
\hline \multicolumn{2}{|c|}{ Handheld Devices $1-3$ years } & 185 & 21.7 \\
\hline & 4-6 years & 239 & 28.0 \\
\hline & $>6$ years & 363 & 42.5 \\
\hline Internet Access & Never & 19 & 2.2 \\
\hline from Handheld & $1-3$ hours per week & 114 & 13.3 \\
\hline \multirow[t]{3}{*}{ Devices } & $4-6$ hours per week & 130 & 15.2 \\
\hline & $7-10$ hours per week & 118 & 13.8 \\
\hline & $>10$ hours per week & 473 & 55.4 \\
\hline
\end{tabular}
M-Learning in the future" $(\mathrm{M}=4.15, \mathrm{SD}=.94)$; "I intend to use $\mathrm{M}$-Learning in the future" $(\mathrm{M}=4.08$; $\mathrm{SD}$ $=.99)$; $\mathrm{EE}$ - "I would find M-learning flexible and easy to use" $(\mathrm{M}=4.08, \mathrm{SD}=.85)$. The three individual items that received the lowest agreement scores were all from the SI construct: "People who influence my behavior will think that I should use M-learning" $(\mathrm{M}=3.25 ; \mathrm{SD}=1.02)$; "The seniors in my college have been helpful in the use of M-learning" $(\mathrm{M}=3.42 ; \mathrm{SD}=1.20)$; and "People who are important to me will think that I should use M-learning" $(\mathrm{M}=3.47 ; \mathrm{SD}=.99)$.

\section{Multiple Linear Regression Model}

A multiple linear regression model was conducted to test if PE, EE, and SI (i.e., independent variables) positively predicted behavioral intention (i.e., dependent variable) to adopt M-learning. All of the assumptions affiliated with the MLR model were tested and found to not be violated: linearity, normality, multicollinearity, independence of residuals, and a lack of outliers. The results of the regression indicated that the omnibus model was a statistically significant predictor of the behavioral intention to use Mlearning, $F=338.83(3,844), p<.001$. The model's $\mathrm{R}^{2}$ indicated a large effect size at 0.55 and taken as a set, the three predictors accounted for $55 \%$ of the variance in behavioral intention to use M-learning, which was also noted at approximately the same effect size value $\left(\mathrm{R}^{2}=54 \%\right)$ by Kijsanayotin, Pannarunothai, and Speedie (2009) with participants from Thailand $(\mathrm{N}=1,187)$.

Table 3 indicates that all of the standardized coefficients $(\beta)$ had a positive relationship with BI and were statistically significant predictors of this outcome, which was also noted by Mtebe and Raisamo (2014) in a study of participants from higher education institutions in East Africa $(\mathrm{N}=823)$. To put the current model's results into analytic perspective, as EE increased by one SD (i.e., EE's SD = .738), the outcome of BI was predicted to increase by .38 of a scale point or greater than one-third of a scale point (i.e., .434 EE's Beta x .876 BI's SD), which is somewhat substantial on a 1 to 5 scale.

\section{Moderated Regression Models}

A set of regression models were run to test for the potential moderating effect of gender between PE, EE, SI, and BI. Testing for a statistically significant interaction effect indicates a moderator's "influence," where moderation examines a variable (gender in this study) that may strengthen or weaken the relationship between dependent and independent variables (Baron \& Kenny, 1986). To "control" for potential collinearity issues and also to arrive at more comprehensible interpretations of the results, an initial data set-up involved group mean centering and creating interaction terms of the independent variables and the potential moderator variable. 
Alshahrani \& Walker

Table 2. Construct Descriptive Statistics

\begin{tabular}{|l|c|c|c|c|}
\hline Performance Expectancy & Mean & $\begin{array}{l}\text { Standard } \\
\text { Deviation }\end{array}$ & Skew & Kurtosis \\
\hline I would find M-learning useful in my learning & 3.89 & .94 & -.93 & .86 \\
\hline $\begin{array}{l}\text { Using M-learning will enable me to accomplish learning } \\
\text { activities more quickly }\end{array}$ & 3.97 & 1.00 & -1.06 & .83 \\
\hline Using M-learning would increase my learning productivity & 3.72 & 1.03 & -.74 & .09 \\
\hline $\begin{array}{l}\text { If I use M-learning, I will increase my chances of getting a better } \\
\text { grade in class }\end{array}$ & 3.78 & 1.06 & -.75 & .04 \\
\hline Effort Expectancy & & & & \\
\hline $\begin{array}{l}\text { My interaction with M-learning would be clear and } \\
\text { understandable }\end{array}$ & 3.73 & .94 & -.81 & .52 \\
\hline It would be easy for me to become skillful at using at M-learning & 4.00 & .92 & -1.06 & 1.26 \\
\hline I would find M-learning flexible and easy to use & 4.08 & .85 & -1.11 & 1.81 \\
\hline $\begin{array}{l}\text { Learning to operate M-learning does not require much effort and } \\
\text { is easy for me }\end{array}$ & 4.00 & .88 & -1.04 & 1.52 \\
\hline Social Influence & & & & \\
\hline $\begin{array}{l}\text { People who influence my behavior will think that I should use } \\
\text { M-learning }\end{array}$ & 3.25 & 1.02 & -.26 & -.41 \\
\hline $\begin{array}{l}\text { People who are important to me will think that I should use M- } \\
\text { learning }\end{array}$ & 3.47 & .99 & -.44 & -.26 \\
\hline $\begin{array}{l}\text { The seniors in my college have been helpful in the use of M- } \\
\text { learning }\end{array}$ & 3.42 & 1.20 & -.54 & -.64 \\
\hline In general, the university supports the use of M-learning & 3.50 & 1.20 & -.60 & -.52 \\
\hline Behavioral Intention & & & & \\
\hline I intend to use M-Learning in the future & 4.08 & .99 & -1.27 & 1.47 \\
\hline I predict that I would use M-Learning in the future & 4.15 & .91 & -1.30 & 1.89 \\
\hline If available, I plan to use M-Learning in the future & 4.15 & .94 & -1.34 & 1.93 \\
\hline
\end{tabular}

Table 3. Multiple Linear Regression Model Results

\begin{tabular}{ccccccccc}
\hline Predictor & $\mathrm{B}$ & $\mathrm{SE}$ & $\beta$ & $\mathrm{t}$ & Sig. & Zero-Order & Partial & $\begin{array}{c}\text { Semi- } \\
\text { Partial }\end{array}$ \\
\hline PE & .297 & .036 & .289 & 8.270 & $.000^{* * *}$ & .661 & .274 & .192 \\
\hline EE & .516 & .041 & .434 & 12.522 & $.000^{* * *}$ & .699 & .396 & .290 \\
\hline SI & .119 & .028 & .114 & 4.216 & $.000^{* * *}$ & .456 & .144 & .098 \\
\hline
\end{tabular}

Note. Performance Expectancy $=(\mathrm{PE})$, Effort Expectancy $=(\mathrm{EE})$, Social Influence $=(\mathrm{SI})$ and statistically significant at $p<.001$.

As Table 4 indicates in the SI moderated model example, there was a statistically significant interaction $(p=.007)$ between SI and gender. Gender did moderate the relationship between SI and BI, where this effect can be seen in Figure 2 with the $\mathrm{R}^{2}$ values of 0.259 and 0.179 for males and females, respectively. Specifically, gender appeared to have a substantial regression effect, where the correlation between SI and BI was 0.509 for males $\left(\sqrt{0.259}\right.$ or its $\left.\mathrm{R}^{2}\right)$, which was somewhat higher than the SI and $\mathrm{BI}$ correlation for females at 0.423 . Figure 2 shows that males started with lower SI and BI values than females, but switched these value positions as SI and BI increased, where males had somewhat higher values on both variables than females near the 5 point scale marker (i.e., the disordinal interaction seen in Figure 2). Additionally, regression results indicated that gender moderated the relationship between PE and BI $(p=.041)$, where the correlations were nearly identical for males $(0.662)$ and females $(0.660)$, with a minor advance to the former group as was also noted by Venkatesh et al. (2003). However, gender did not moderate the relationship between $\mathrm{EE}$ and $\mathrm{BI}(p=.773)$. 
Table 4. Moderated SI Regression Model Results

Coefficients

\begin{tabular}{|l|c|c|c|c|c|}
\hline \multicolumn{1}{|c|}{ Model } & \multicolumn{2}{c|}{$\begin{array}{c}\text { Unstandardized } \\
\text { Coefficients }\end{array}$} & $\begin{array}{c}\text { Standardized } \\
\text { Coefficients }\end{array}$ & $\mathrm{t}$ & Sig. \\
\cline { 2 - 6 } & $\mathrm{B}$ & SE & $\beta$ & & \\
\hline & 4.120 & .027 & & 155.278 & $<.001$ \\
\hline Gender Centered & .250 & .054 & .140 & 4.630 & $<.001$ \\
\hline $\begin{array}{l}\text { SI Centered } \\
\text { Censtant })\end{array}$ & .503 & .032 & .480 & 15.792 & $<.001$ \\
\hline $\begin{array}{l}\text { Gender Centered*SI } \\
\text { Centered }\end{array}$ & -.173 & .064 & -.082 & -2.703 & .007 \\
\hline
\end{tabular}

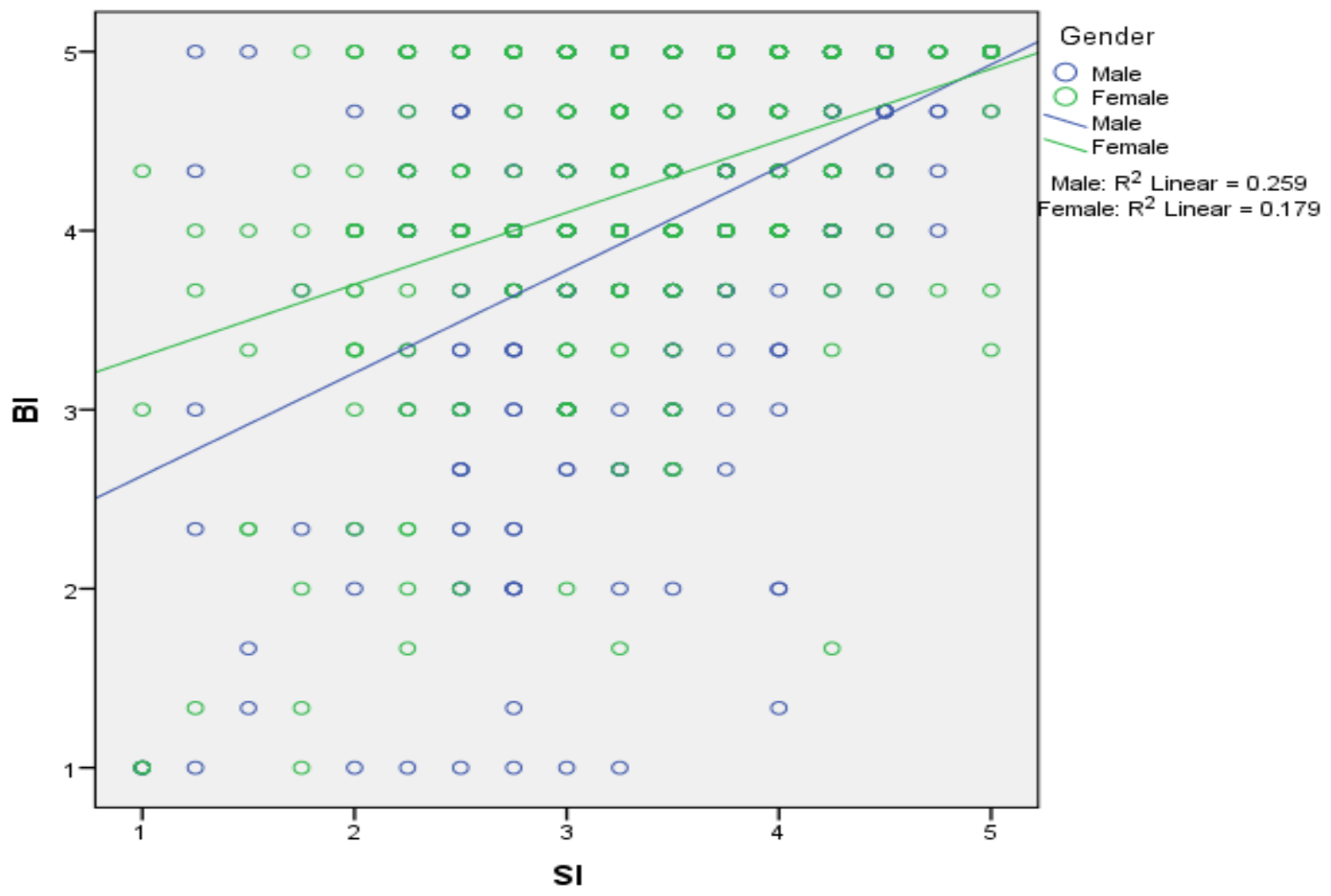

Figure 2. Gender as a moderator of the relationship between SI and BI: Disordinal interaction.

In summation, the empirical evidence from the sample data, indicated that the MLR hypothesis $\left(\mathrm{H}_{1}\right)$ was supported, where PE $(\beta=.289, p<.001), \mathrm{EE}(\beta=.434, p<.001)$, and SI $(\beta=.114, p<.001)$ all had positive, statistically significant relationships with behavioral intention of M-learning (i.e., these variables were predictors of $\mathrm{BI}$ ), and also accounted for a large portion of the variance in BI at 55\%. Further, two of the three moderated regression hypotheses were supported: $\mathrm{H}_{2}$ (the relationship between PE and BI toward using M-learning was moderated by the gender) and $\mathrm{H}_{4}$ (The relationship between SI and BI toward using M-learning was moderated by the gender).

\section{Internal Consistency}

\section{Internal Score Structure}

Cronbach's alpha $(\alpha)$ was used to estimate internal score consistency (i.e., item inter-relatedness) for each of the sub-scales. This internal consistency estimate indicated that the sub-scales had reasonably high score internal consistency (or item inter-relatedness) with $\mathrm{PE}=0.86$ (95\% confidence intervals (CI) $0.85,0.88) ; \mathrm{EE}=0.84$ (CI 0.82, 0.86); $\mathrm{SI}=0.75$ (CI 0.72, 0.78); and $\mathrm{BI}=0.91$ (CI 0.90, 0.92). The 
recommended minimum value for score reliability in basic (or applied) exploratory research is $\alpha \geq .70$ and $\alpha \geq .80$ for confirmatory intent (Nunnally, 1978). Correspondingly, Venkatesh et al. (2003) found that the original UTAUT sub-scales had estimated, cross-validated $\alpha$ values of $\mathrm{PE}=0.91, \mathrm{EE}=0.91, \mathrm{SI}=0.92$, and $\mathrm{BI}=0.89$. Whereas, similar to the results from the aforementioned current study, a modified version of the UTAUT by Mtebe and Raisamo (2014) found $\alpha$ values of $\mathrm{PE}=0.88, \mathrm{EE}=0.82, \mathrm{SI}=0.75$, and BI $=0.85$.

\section{Construct Reliability}

Since latent constructs and the uni-dimensionality of this version of the UTAUT model has been identified and verified through previous research (Jairak et al., 2009; Kijsanayotin et al., 2009), a confirmatory factor analysis was conducted as a means to compute construct reliability (CR) as well as the subsequent validity indices. CR was estimated for the obtained scores from the UTAUT model via the following equation:

$$
C R=\frac{\Sigma(L)^{2}}{\Sigma(L)^{2}+\Sigma(\Delta)}
$$

where; $L=$ Standardized factor loadings and $\Sigma(\Delta)=1-\mathrm{h}^{2}$ (i.e., $\mathrm{h}^{2}$ indicates a coefficient communality)

Results indicated robust construct reliability, where the scores for each construct had high internal consistency, with estimates for $\mathrm{PE}=0.87 ; \mathrm{EE}=0.87 ; \mathrm{SI}=0.81$; and $\mathrm{BI}=0.92$. As noted earlier with the Cronbach's $\alpha$ analysis, the construct with 'lower' score internal consistency was SI. The desired CR threshold is > .70 (Hair, Anderson, Tatham, \& Black, 1998).

\section{Convergent Validity}

Convergent validity $(\mathrm{CV})$ values for the constructs in the UTAUT model were estimated by Fornell and Larcker's (1981) Average Variance Extracted (AVE):

$$
A V E=\frac{\Sigma\left(\mathrm{L}^{2}\right)}{N}
$$

where; $\Sigma\left(\mathrm{L}^{2}\right)=$ The sum of the standardized regression weights squared

Results indicated robust $\mathrm{CV}$, where the items used to measure each construct had a high proportion of variance in common, with estimates for $\mathrm{PE}=0.62$; $\mathrm{EE}=0.63 ; \mathrm{SI}=0.52$; and $\mathrm{BI}=0.80$. The preferred AVE cut-point is $>.50$ (Fornell \& Larcker).

\section{Discriminant Validity}

To examine the extent to which an individual model construct was divergent from other constructs within the larger UTAUT model, the AVE estimate for two constructs, per Fornell and Larcker (1981), ought to be greater in value than the construct pair's shared variance or SIC (i.e., squared inter-construct correlation). Results indicated that the SI $\leftrightarrow$ EE AVE pairing $=(0.52,0.63)>\mathrm{SIC}=0.41$ and the $\mathrm{PE} \leftrightarrow$ SI AVE pairing $=(0.62,0.0 .52)>$ SIC $=0.44$, which signified a desired level of discriminant validity. However, the $\mathrm{PE} \leftrightarrow \mathrm{EE} \mathrm{AVE} \mathrm{pairing}=(0.62,0.63)<\mathrm{SIC}=0.78$, which, in this particular case, specified that this construct combination had compromised discriminability.

\section{Discussion and Implications for the Literature}

In terms of the advancing the knowledge in the domain of technology acceptance research and providing overall support for Venkatesh et al.'s (2003) UTAUT model, the current study's model explained $55 \%$ of the variance in students' behavioral intentions. Additionally, this current effect result was also noted in a similar model's effect (55\%) from the United Kingdom $(\mathrm{N}=174)$ by Abu-Al-Aish and Love (2013). Conversely, with a fairly similar framework, the Mtebe and Raisamo (2014) model's effect size $\left(\mathrm{R}^{2}=28 \%\right.$; $\left.\mathrm{N}=823\right)$ was half of the magnitude of the current study's effect, which exemplifies the aforementioned effect size range that is possible with this version of the UTAUT model. Further, and consistent with previous research, PE, EE, and SI were all statistically significant, positive predictors of behavioral intention to use M-learning (Jairak et al., 2009; Lowenthal, 2010; Mtebe \& Raisamo; Wang et al., 2009).

Additional results obtained from the present study, related to M-learning at a Saudi Arabian higher education institution, indicated that $\mathrm{PE}$ was a statistically significant, positive predictor of behavioral intention to use M-learning $(\beta=.289, p<.001)$, which is congruent with findings from previous studies 
(Jairak et al., 2009; Lowenthal, 2010; Venkatesh et al., 2003; Wang et al., 2009). This result may imply that students in higher education, in general and also in Saudi Arabia, perceived that M-learning was beneficial. The results from this research also suggested that perceived usefulness was a necessary component of students' intention to adopt mobile device technology for academic purposes.

Further, it was found that EE was a statistically significant, positive predictor of behavioral intention to use M-learning ( $\beta=0.434, p<.001$ ), which is also consistent with findings from Jairak et al. (2009), Lowenthal (2010), Venkatesh et al. (2003), and Wang et al., (2009). This result suggested students perceived that M-learning should be 'simple' in application and use. Unlike previous UTAUT studies conducted by Venkatesh et al. (2003) and Wang et al., who found that PE was the strongest predictor of behavioral intention to use M-learning, the findings obtained from the present study indicated that EE was a stronger predictor than PE. This change in rank order of predictor strength may be due to participating students' familiarity with mobile device technology, as noted previously in the demographic section of his study. That is, using these devices appears to be routine for many participants. Thus, students may perceive employing mobile devices for academic learning as a similar process to using them for personal consumption and entertainment purposes.

The results of this study found that SI was a statistically significant, positive predictor of BI ( $\beta=$ $0.114, p<.001)$, but was also the weakest of the three independent variables in the regression model. This finding is in accord with Wang et al. (2009) and Abu-Al-Aish and Love (2013) who demonstrated that a student's behavioral intention decision was influenced by other relationship-based, social influences such as peers, instructors, or parents.

Finally, it was found that participants' gender did moderate the effect of both PE and SI on the outcome of behavioral intentions. Both of the SI and BI and PE and BI relationships had substantial effects derived from the moderator gender. These current results are congruent with findings from Venkatesh et al. (2003).

\section{Implications for Practice}

Open-ended question results indicated, from an exploratory perspective, that it would be practical to provide students with services, content instruction, and information inside and outside of traditional, higher education learning spaces. That is, students and instructors could use mobile devices, via Mlearning, to access information (often times large amounts) and learning activities as well as engage in an educational process in a ubiquitous fashion. Students could utilize mobile devices to interact, connect, communicate, and collaborate with instructors and other students and participate in a course or seek content by accessing rich digital resources.

Particularly, student perspective indicated that incorporating M-learning, such as short message service (i.e., text messaging), where students could interact with peers and instructors for educational purposes, is viewed as an optimal medium for the current teaching and learning environment. For instance, students could utilize texting for posing questions or sharing views or information throughout the duration of a quarter or a semester in various teaching and learning environments. Additionally, student perception indicated that incorporating instructional YouTube videos in the teaching and learning process would provide enhancement in learning skills. For example, students could use the multimedia potential of instructional YouTube videos to engage with new topics and apply their knowledge and understanding of these foci within and beyond the classroom learning space. Summarily, in both instances of messaging and virtually extending locale proximity, Sheer and Rice (2017) recently found, "In a broader sense, mobile messaging extends work connectivity beyond the boundaries of work units and those of organizations..." (p. 100).

\section{Study Limitations}

\section{Limitations and Future Research}

The scope of the present study was limited to a convenience sample at a single university and geographical setting and; thus, the results may have compromised generalizability to auxiliary higher education entities in other countries. Further, there is caution noted with UTAUT's general use when not recognizing the aspect that varying cultural contexts may introduce to the model's inter-relationships (AlGahtani, Hubona, \& Wang, 2007; Thomas, Singh, \& Gaffar, 2013). The participants completed an Arabic version of the UTAUT survey, which was back translated into English, so a level of accuracy may have been conceded to some degree in this language conversion process. Lastly, this study, via its employment of the UTAUT model, did not investigate actual technology usage (i.e., behavior use), but rather 
predictions of use through perceptional, behavioral intention. Some researchers (Sheeran, 2002) have questioned the model's shortcomings in this aforementioned area, which is referred to as the 'intentionbehavior gap.' Although this last point is regarded as a potential limitation, it should be noted that the relationship between behavioral intention and actual behavior has been empirically supported through prior research (Davis, 1989; Taylor \& Todd, 1995; Venkatesh \& Davis, 2000).

\section{Future Research}

Several opportunities are available to extend this research. The following are some suggestions for future research on the acceptance of M-learning. A replication study at another Saudi Arabian institution of higher education could add to generalizability. Additionally, a study that extends globally to other countries' higher education institutions is valuable because attitudes and adoption behaviors of mobile devices in other cultural contexts differ from those in Saudi Arabia. Moreover, a research study could investigate M-learning acceptance among graduate students and higher education administrators and instructors; particularly in cultural and educational settings that emulate a context such as Saudi Arabia.

\section{References}

Azen, R., \& Budescu, D. V. (2003). The dominance analysis approach to comparing predictors in multiple regression. Psychological Methods, 8, 129-148.

Abu-Al-Aish, A., \& Love, S. (2013). Factors influencing students' acceptance of m-learning: An investigation in higher education. The International Review of Research in Open and Distance Leaning, 14(5), 82-107.

Ajzen, I. (1991). The theory of planned behavior. Organizational Behavior and Human Decision Processes, 50(2), 179-211.

Al-Gahtani, S. S., Hubona, G. S., \& Wang, J. (2007). Information technology (IT) in Saudi Arabia: Culture and the acceptance and use of IT. Information \& Management, 44, 681-691.

Anderson, J. E., Schwager, P. H., \& Kerns, R. L. (2006). The drivers for acceptance of tablet PCs by faculty in a college of business. Journal of Information Systems Education, 17(4), 429-440.

Bandura, A. (1986). Social foundations of thought and action: A social cognitive theory. Englewood Cliffs, NJ: Prentice-Hall.

Baron, R. M., \& Kenny, D. A. (1986). The moderator-mediator variable distinction in social psychological research: Conceptual, strategic, and statistical considerations. Journal of Personality \& Social Psychology, 51, 1173-1182.

Baron, S., Patterson, A., \& Harris, K. (2006). Beyond technology acceptance: understanding consumer practice. International Journal of Service Industry Management, 17(2), 111-135.

Chen, J. L. (2011). The effects of education compatibility and technological expectancy on e-learning acceptance. Computers \& Education, 57(2), 1501-1511.

Chen, B., Seilhamer, R., Bennett, L., \& Bauer, S. (2015). Students' mobile learning practices in

higher education: A multi-year study. EDUCAUSE Review. Retrieved from http://er.educause.edu/articles/2015/6/students-mobile-learning-practices-in-higher-education-amultiyear-study

Chong, A. Y. L. (2013). Predicting m-commerce adoption determinants: A neural network approach. Expert Systems with Applications, 40(2), 523-530.

Communications and Information Technology Commission. (2015). Annual report 2015. Retrieved from http://www.citc.gov.sa/english/Pages/default.apx

Dahlstrom, E., \& Bichsel, J. (2014). ECAR study of undergraduate students and information technology. Retrieved from http://www.educause.edu/ecar

Davis, F. D. (1989). Perceived usefulness, perceived ease of use, and user acceptance of information technology. MIS Quarterly, 13(3), 319-339.

Davis, F. D., Bagozzi, R. P., \& Warshaw, P. R. (1992). Extrinsic and intrinsic motivation to use computers in the workplace. Journal of Applied Social Psychology, 22(14), 1111-1132.

Dillon, A., \& Morris, M. (1996). User acceptance of information technology: Theories and models. Annual Review of Information Science and Technology. Medford, NJ: Information Today.

Donaldson, R. L. (2011). Student acceptance of mobile learning (Doctoral dissertation). Florida State University. 
El-Hussein, M. O., \& Cronje, J. C. (2010). Defining mobile learning in the higher education landscape. Journal of Educational Technology \& Society, 13(3), 12-21.

Faul, F., Erdfelder, E., Buchner, A., \& Lang, A. G. (2009). Statistical power analyses using G*Power 3.1: Tests for correlation and regression analyses. Behavior Research Methods, 41, 1149-1160.

Faul, F., Erdfelder, E., Lang, A. G., \& Buchner, A. (2007). G*Power 3: A flexible statistical power analysis program for the social, behavioral, and biomedical sciences. Behavior Research Methods, 39 , 175-191.

Fishbein, M., \& Ajzen, I. (1975). Belief, attitude, intention and behavior: An introduction to theory and research. Reading, MA: Addison-Wesley.

Fornell, C., \& Larcker, D. F. (1981). Evaluating structural equation models with unobservable variables and measurement error. Journal of Marketing Research, 18, 39-50.

Hair, J. F., Anderson, R. E., Tatham, R. L., \& Black, W. C. (1998). Multivariate data analysis with readings (5th ed.). Upper Saddle River, NJ: Prentice Hall.

International Telecommunication Union (2012). Middle East's mobile-subscription count will cross 250million mark in 2012. Retrieved from: http://www.itu.int/ITUD/ict/newslog/Middle+Easts+Mobilesubscription+Count+Will+Cross+250million+Mark+In+2012.aspx

Irby, T. L., \& Strong, R. (2013). Agricultural education students' acceptance and self-efficacy of mobile technology in classrooms. NACTA Journal, 57(1), 82-87.

Jairak, K., Praneetpolgrang, P., \& Mekhabunchakij, K. (2009). An acceptance of mobile learning for higher education students in Thailand. Special Issue of the International Journal of Computer, the Internet and Management, 17(3), 17-18.

Kijsanayotina, B., Pannarunothaib, S., \& Speedie, S. M. (2009). Factors influencing health information technology adoption in Thailand's community health centers: Applying the UTAUT model. International Journal of Medical Informatics, 78, 404-416.

Krueger, N. F., \& Brazeal, D. V. (1994). Entrepreneurial Potential and Potential Entrepreneurs. Entrepreneurship: Theory \& Practice, 18(3), 91-104.

Liu, Y., Han, S., \& Li, H. (2010). Understanding the factors driving m-learning adoption: A literature review. Campus - Wide Information Systems, 27(4), 210-226.

Lowenthal, J. (2010). Using mobile learning: Determinates impacting behavioral intention. The American Journal of Distance Education, 24(4), 195-206.

Marchewka, J. T., Liu, C. L., \& Kostiwa, K. (2007). An application of the UTAUT model for understanding student perceptions using course management software. Communications of the IIMA, 7(2), 93-104.

Moghavvemi, S., Salleh, N. A. M., Zhao, W., \& Mattila, M. (2012). The entrepreneur's perception on information technology innovation adoption: An empirical analysis of the role of precipitating events on usage behavior. Innovation: Management, Policy \& Practice, 14, 231-246.

Moran, M., Hawkes, M., \& El Gayar, O. (2010). Tablet personal computer integration in higher education: Applying the unified theory of acceptance and use technology model to understand supporting factors. Journal of Educational Computing Research, 42(1), 79-101.

Mtebe, J. S., \& Raisamo, R. (2014). Investigating students' behavioural intention to adopt and

use mobile learning in higher education in East Africa. International Journal of Education and Development using Information and Communication Technology, 10(3), 4-20.

Nunnally, J. C. (1978). Psychometric theory (2nd ed.). New York: McGraw-Hill.

Peng, H., Su, Y. J., Chou, C. \& Tsai, C.C. (2009). Ubiquitous knowledge construction: Mobile learning re-defined and a conceptual framework. Innovations in Education \& Teaching International, 46(2), 171-183.

Pew Research Center. (2016). Mobile fact sheet. Retrieved from http://www.pewinternet.org/factsheet/mobile/

Poushter, J. (2016). Smartphone ownership and internet usage continues to climb in emerging economies. Retrieved from http://www.pewglobal.org/2016/02/22/smartphone-ownership-and-internet-usagecontinues-to-climb-in-emerging-economies/

Rogers, E. M. (1962). Diffusion of innovations. New York: Free Press.

Schepman, A., Rodway, P., Beattie, C., \& Lambert, J. (2012). An observational study of undergraduate students' adoption of (mobile) note-taking software. Computers in Human Behavior, 2(2), 308-317. 
Sharples, M., Taylor, J., \& Vavoula, G. (2007). A theory of learning for the mobile age. In R. Andrews \& C. Haythornthwaite (Eds.), The Sage handbook of e-learning research (pp. 221-471). London: Sage.

Sheer, V., C., \& Rice, R. E. (2017). Mobile instant messaging use and social capital: Direct and indirect associations with employee outcomes. Information \& Management, 54, 90-102.

Sheeran, P. (2002). Intention-behavior relations: A conceptual and empirical review. European Review of Social Psychology, 12, 1-36.

Taylor, S., \& Todd, P. A. (1995). Assessing IT usage: The role of prior experience. MIS Quarterly, 19(2), 561-570.

Thomas, T. D., Singh, L., \& and Gaffar, K. (2013). The utility of the UTAUT model in explaining mobile learning adoption in higher education in Guyana. International Journal of Education and Development using Information and Communication Technology, 9, 71-85.

Thompson, R. L., Higgins, C. A., \& Howell, J. M. (1991). Personal computing: Toward a conceptual model of utilization. MIS Quarterly, 15(1), 124-143.

Venkatesh, V., \& Davis, F. D. (2000). A theoretical extension of the technology acceptance model: Four longitudinal field studies. Management Science, 46(2), 186-204.

Venkatesh, V., Morris, M. G., Ackerman, P. L. (2000). A longitudinal field investigation of gender differences in individual technology adoption decision making processes. Organizational Behavior and Human Decision Processes, 83, 33-60.

Venkatesh, V., Morris, M. G., Davis, G. B., \& Davis, F. D. (2003). User acceptance of information technology: Toward a unified view. MIS Quarterly, 27(3), 425-478.

Venkatesh, V., Thong, J. Y. L.., \& Xu, X. (2012). Consumer acceptance and use of information technology: Extending the Unified Theory of Acceptance and Use of Technology. MIS Quarterly, $36(1), 157-178$.

Wang, H. Y., \& Wang, S. H. (2010). User acceptance of mobile internet based on the Unified Theory of Acceptance and Use of Technology: Investigating the determinants and gender differences. Social Behavior and Personality: an international journal, 38(3), 415-426.

Wang, Y., Wu, M., \& Wang, H. (2009). Investigating the determinants and age and gender differences in the acceptance of mobile learning. British Journal of Educational Technology, 40(1), 92-118. 